\title{
Estabilidade fenotípica de genótipos de morangueiro submetidos a número variável de subcultivos in vitro
}

\author{
Phenotypic stability of strawberry genotypes subjected to variable number of in vitro subcultures
}

\author{
Andréa Pereira da Fonseca $^{\mathrm{I}^{*}}$ Erika Caitano da Silva ${ }^{\mathrm{I}}$ Maurício Ballesteiro Pereira ${ }^{\mathrm{I}}$ \\ Roberto Pedroso de Oliveira ${ }^{I I}$ Ana Lúcia Cunha Dornelles ${ }^{I}$
}

RESUMO

Objetivando analisar o número de subcultivos que permita a multiplicação do morangueiro, sem que ocorram alterações nas características fenotípicas dos clones submetidos a esse processo, explantes dos genótipos Aromas, Camarosa e 'Camino Real'foram submetidos, em uma primeira etapa, a 12 ciclos de subcultivos in vitro $e$, no ano seguinte, explantes dos mesmos genótipos, das mesmas plantas matrizes, foram subcultivados por três ciclos. Após a fase de aclimatização, as mudas foram transplantadas para canteiros, e o experimento conduzido segundo delineamento em blocos casualizados em esquema fatorial $3 \times 2$ (genótipos e níveis de subcultivos). As características avaliadas foram: altura da planta e comprimento da raiz (cm), massas fresca e seca da parte aérea e da raiz $(g)$ e número de estolóes por planta. Na avaliação a campo das características fenotípicas, não foram observadas diferenças significativas entre os dois níveis de subcultivos. As cultivares 'Camarosa' e 'Camino Real' apresentaram maior variação entre os dois níveis de subcultivos, sendo as maiores variações observadas em plantas submetidas a três subcultivos. Com 12 subcultivos in vitro de plantas de morangueiro, das cultivares 'Aromas', 'Camarosa' e 'Camino Real', é possível obter maior número de mudas micropropagadas sem alterações nas características fenotípicas. A cultivar 'Aromas' apresentou uma maior estabilidade nas características fenotípicas estudadas em relação aos diferentes ciclos de subcultivo in vitro.

Palavras-chave: Fragaria ananassa (Duch.), cultura de tecidos, caracteres quantitativos.

\section{ABSTRACT}

In order to increase the availability of healthy strawberry seedlings, this study aimed to analyze the number of subcultures that enables multiplication on a large scale, without the occurrence of changes in phenotypic characteristics of clones through the process of in vitro micropropagation. In a first step, explants of the cultivars 'Aromas', 'Camarosa' and 'Camino
Real', at the Laboratory of Plant Tissue Culture, were submitted to twelve subculture cycles, and in the following year, explants of the same cultivars, from the same mother plants, were subcultured for three cycles. The acclimatization and evaluation of the plants in the field were conducted in a greenhouse at the Horticulture Sector of the Instituto of Agronomia of the Universidade Federal Rural do Rio de Janeiro. The experimental design was randomized blocks in a $3 \times 2$ factorial, (genotypes and subculture levels). The characteristics evaluated were plant height and root length $(\mathrm{cm})$, fresh mass and dry mass of shoots and roots $(\mathrm{g})$ and number of stolons per plant. In the field evaluation, no differences between the two levels of subcultures were observed. Cultivars 'Camarosa' and 'Camino Real' showed the highest variation between the two levels of subcultures, with the greatest variations observed in plants subjected to three subcultures. With twelve in vitro subcultures of strawberry plants, of cultivars 'Aromas', 'Camarosa' and 'Camino Real', it is possible to obtain greater number of plantlets without changes in phenotypic characteristics. The cultivar 'Aromas' showed greater stability in phenotypic characteristics studied in relation to different cycles of in vitro subculture.

Key words: Fragaria ananassa (Duch.), tissue culture, quantitative characters.

\section{INTRODUÇÃO}

O morangueiro Fragaria x ananassa (Duch.) é uma herbácea perene cultivada como anual que pertence à família Rosaceae. É uma cultura muito suscetível a doenças viróticas e a microrganismos, como fungos e bactérias e, através da propagação por via vegetativa, utilizando estolões de plantas infestadas, ocorre a disseminação de doenças (CALVETE et al., 2002). Mudas sadias

\footnotetext{
'Departamento de Genética, Instituto de Biologia, Universidade Federal Rural do Rio de Janeiro (UFRRJ), Seropédica, RJ, Brasil.

IEmbrapa, Centro de Pesquisa Agropecuária de Clima Temperado, CP 403, 96001-750, Pelotas, RS, Brasil. E-mail: pf.andrea@ gmail.com.

*Autor para correspondência.
} 
de morangueiro podem ser obtidas sem maiores dificuldades por meio da técnica de culturas de tecidos in vitro, utilizando como explante ápices caulinares, visto que o tecido meristemático localizado nas gemas em crescimento não possui um sistema vascular desenvolvido e que a maioria dos vírus infecta as plantas de forma sistêmica (GOMIDE, 2004).

De acordo com OLIVEIRA et al. (2005), as cultivares de morangueiro são bastante responsivas in vitro, com taxas de multiplicação superiores às de outras espécies, como banana e abacaxi. Dessa forma, o emprego da técnica de cultura de tecidos possibilita a produção do maior número de plantas possível no menor espaço de tempo, por meio de vários ciclos de multiplicação in vitro. Entretanto, durante a fase de multiplicação, alguns aspectos qualitativos importantes devem ser considerados, como, por exemplo, a obtenção de uma taxa média de multiplicação satisfatória com o mínimo de variação de explante para explante, além de aspectos relacionados à homogeneidade do material, como a composição do meio de cultivo, além dos níveis de fitorreguladores e o número de subcultivos (RANCILLAC \& NOURISSEAU, 1989). Segundo D’AMATO (1986), não se pode excluir que alguns fitorreguladores, a certas concentrações ou em combinações com outros fitorreguladores e/ou constituintes particulares do meio de cultivo, podem agir como agentes mutagênicos.

No que diz respeito ao número de subcultivos, para o morangueiro, é recomendado que sejam realizadas apenas cinco ciclos de subcultivos com intervalos de 20-30 dias (OLIVEIRA et al., 2005), embora na Europa sejam toleradas até 10 etapas de multiplicação, não sendo aconselhável ultrapassar este valor (EPPO, 2008). Em plantas de Fragaria, com o aumento do número de subcultivos, podem ocorrer variações nas características fenotípicas, como altura e vigor das plantas, tamanho e formato de frutos (DEBERGH \& READ, 1991). Segundo ARRUDA et al. (2006), a maioria dos trabalhos aborda a variação encontrada em plantas regeneradas por meio da técnica de cultura de tecidos.

Segundo CASSELLS \& CURRY (2001), à cultura de tecidos estão associados problemas de ordem fisiológica, genética e epigenética. Sob o ponto de vista de propagação clonal in vitro, transformação genética e/ou preservação de germoplasma, a variação somaclonal não é desejável, sendo importante conhecer a frequência, a distribuição genômica, os mecanismos e os fatores que influenciam esse fenômeno, representando um desafio a ser considerado sob o ponto de vista teórico e prático (POLANCO \& RUIZ, 2002).
Este trabalho teve como objetivo avaliar se os diferentes ciclos de subcultivos in vitro afetam as características fenotípicas dos clones de morangueiro.

\section{MATERIAL E MÉTODOS}

A fase de multiplicação e enraizamento in vitro de plântulas de morangueiro foi desenvolvida no Laboratório de Cultura de Tecidos Vegetais do Departamento de Fitotecnia do Instituto de Agronomia da Universidade Federal Rural do Rio de Janeiro e foi dividido em duas etapas. Na primeira etapa, foram realizados 12 subcultivos e, na segunda, três subcultivos, com intervalos médios de 30 dias. Foram utilizadas as cultivares 'Aromas', 'Camarosa' e 'Camino Real', provenientes da Embrapa Clima Temperado, Pelotas-RS. Para a realização dos processos de multiplicação e enraizamento das plântulas, foi seguido o protocolo para a produção de matrizes de morangueiro por meio de cultura de tecidos utilizado pela Embrapa Clima Temperado (OLIVEIRA et al., 2005).

No processo de aclimatização, as plântulas enraizadas in vitro foram retiradas do frasco e as raízes foram lavadas em água corrente, e, em seguida, transplantadas para bandejas de polipropileno de 165 células com substrato comercial Plantmax ${ }^{\circledR}$. O sistema de irrigação utilizado durante essa fase foi o de nebulização intermitente em forma de névoa. As mudas foram mantidas em casa de vegetação sob túnel plástico transparente durante 45 dias.

Após o período de aclimatização, foi instalado o experimento para avaliação a campo das alterações fenotípicas em clones de morangueiro. $\mathrm{O}$ delineamento experimental utilizado foi o de blocos casualizados em esquema fatorial $3 \times 2$, sendo um dos fatores as cultivares ('Aromas', 'Camarosa' e 'Camino Real') e o outro, o número de subcultivos (três e doze) com quatro repetições e 16 plantas por parcela.

Para a análise dos caracteres massas fresca e seca da parte aérea e da raiz, altura da planta e comprimento da raiz após a fase de aclimatização e a campo e número de estolões, foi feita análise de variância em cada combinação genótipo e subcultivo, considerando como efeito apenas o bloco, com o objetivo de determinar a variância média dentro dos blocos para cada combinação. Para cada genótipo, as variâncias dos subcultivos três e doze foram comparadas pelo teste $\mathrm{F}$, dividindo a variância maior pela menor. Foram calculadas as médias referentes a cada bloco para cada combinação genótipo e subcultivo. Esses valores foram submetidos à análise de variância, considerando o modelo fatorial 
(genótipos e subcultivos), com quatro repetições em blocos casualizados. Foi realizada análise do fatorial seguindo-se a decomposição de subcultivos dentro de genótipo (STEEL \& TORRIE, 1981).

A comparação das médias para subcultivos foi feita de acordo com o teste F (ANOVA). Para cultivares, quando o valor de $\mathrm{F}$ correspondente foi significativo, foi realizado o teste de Tukey a 5\% de probabilidade, dentro de cada subcultivo e para a média geral.

\section{RESULTADOS E DISCUSSÃO}

Ao final da fase de aclimatização, a avaliação da altura média da parte aérea das plântulas demonstrou, pelo teste de Tukey, que não houve diferença significativa entre as cultivares. Levando em conta os dois níveis de subcultivos, a maior altura média da parte aérea de $6,83 \mathrm{~cm}$ foi observada no $12^{\circ}$ subcultivo (Tabela 1). GOMIDE (2004) observou que as mudas de morangueiro submetidas a nove ciclos de subcultivos in vitro apresentaram maior altura que as demais mudas subcultivadas por menor tempo.

Não houve interação significativa entre subcultivos e genótipos, no entanto, a decomposição de subcultivo dentro de genótipo mostrou que houve diferença significativa entre os subcultivos para a cultivar 'Camarosa' e para a cultivar 'Camino Real', que apresentaram maiores valores médios de altura da parte aérea de 7,07 e $6,95 \mathrm{~cm}$ com 12 subcultivos, respectivamente.

Não foi observada diferença significativa entre as médias do comprimento da raiz das plântulas de morangueiro submetidas a três e 12 subcultivos após a fase de aclimatização. Em relação à média das cultivares, o teste de Tukey mostrou que não houve diferença significativa entre as cultivares 'Camarosa' e 'Camino Real', no entanto, as plântulas dessas cultivares apresentaram comprimento médio de raiz superior ao da cultivar 'Aromas' (Tabela 1). Não houve interação significativa entre subcultivos e cultivares, entretanto, a decomposição de subcultivo dentro de genótipo mostrou que houve diferença significativa entre os subcultivos para a cultivar 'Camino Real', que apresentou o maior valor médio de comprimento da raiz de $11,99 \mathrm{~cm}$ com 12 subcultivos.

Em termos de variação entre os dois níveis de subcultivos para as cultivares 'Camarosa' e 'Camino Real', não foi observada diferença significativa na altura da parte aérea das plântulas após a fase de aclimatização. Por outro lado, a cultivar 'Aromas' apresentou diferença significativa nos valores de variância entre os dois níveis de subcultivos. Para o comprimento da raiz, após a fase de aclimatização, foi verificado que não houve diferença significativa em termos de variação entre os dois níveis de subcultivos para as cultivares 'Aromas' e 'Camino Real', contudo, a cultivar 'Camarosa' apresentou variação no comprimento da raiz entre os dois níveis de subcultivos. As maiores variações foram observadas nas plantas submetidas a 12 subcultivos, conforme mostra o teste $\mathrm{F}$ (Tabela 2). Esses resultados indicam que o número de subcultivos somente exerce influência em determinada característica e cultivar e que a variação no comportamento das cultivares em relação às características estudadas pode ser devida

Tabela 1 - Valores médios da altura da parte aérea e do comprimento da raiz de plântulas após a fase de aclimatização das cultivares 'Aromas', 'Camarosa' e 'Camino Real', submetidas a três e doze subcultivos. UFRRJ, Seropédica, RJ, 2009.

\begin{tabular}{|c|c|c|c|}
\hline Cultivares & 3 & 12 & Média \\
\hline 'Aromas' & $5,82 \mathrm{Aa}$ & $6,48 \mathrm{Aa}$ & $6,15 \mathrm{~A}$ \\
\hline 'Camarosa' & $5,70 \mathrm{Ab}$ & 7,07 Aa & $6,38 \mathrm{~A}$ \\
\hline 'Camino Real' & $6,20 \mathrm{Ab}$ & $6,95 \mathrm{Aa}$ & $6,57 \mathrm{~A}$ \\
\hline Média & $5,90 \mathrm{~b}$ & $6,83 \mathrm{a}$ & \\
\hline 'Aromas' & 9,87 $\mathrm{Aa}$ & $9,37 \mathrm{Ba}$ & $9,62 \mathrm{~B}$ \\
\hline 'Camarosa' & 9,93 Aa & $11,01 \mathrm{Aa}$ & $10,47 \mathrm{~A}$ \\
\hline 'Camino Real' & $10,19 \mathrm{Ab}$ & $11,99 \mathrm{Aa}$ & $11,09 \mathrm{~A}$ \\
\hline Média & $9,99 \mathrm{a}$ & $10,79 \mathrm{a}$ & \\
\hline
\end{tabular}

Médias seguidas de mesma letra maiúscula, nas linhas, não diferem significativamente entre si, pelo teste de Tukey (5\%), e letras minúsculas, nas colunas, não diferem significativamente entre si, com base no teste $\mathrm{F}(5 \%)$.

Ciência Rural, v.43, n.8, ago 2013. 
Tabela 2 - Valores das variâncias dentro das cultivares 'Aromas', 'Camarosa' e 'Camino Real' e dos subcultivos três e doze e teste F para as características altura da parte aérea (APA) e comprimento da raiz (CR) das plântulas após a fase de aclimatização. UFRRJ, Seropédica, RJ, 2009.

\begin{tabular}{|c|c|c|c|c|c|c|c|c|c|}
\hline \multirow{2}{*}{ Característica } & \multicolumn{3}{|c|}{--------------- 'Aromas'---------------- } & \multicolumn{3}{|c|}{-'Camarosa'--------------- } & \multicolumn{3}{|c|}{ 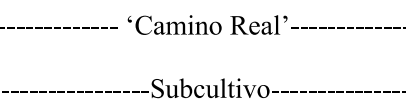 } \\
\hline & 3 & 12 & $\mathrm{~F}$ & 3 & 12 & $\mathrm{~F}$ & 3 & 12 & $\mathrm{~F}$ \\
\hline $\mathrm{APA}$ & 2,21 & 4,05 & $1,83 *$ & 4,77 & 4,62 & 1,03 ñs & 3,53 & 2,90 & 1,22 ñs \\
\hline $\mathrm{CR}$ & 15,68 & 12,38 & 1,27 ñs & 21,78 & 13,08 & $1,66 *$ & 14,59 & 10,29 & 1,42 ñs \\
\hline
\end{tabular}

* Significativo em nível de 5\% de probabilidade (Teste F)

ñs - não significativo.

à resposta do genótipo ao número de subcultivos a que foi submetido. SANTIAGO et al. (2012) também verificaram comportamento diferenciado entre as cultivares de batatas 'Asterix' e 'Macaca' micropropagadas com relação às características morfológicas estudadas. Além disso, com relação ao tempo de subcultivo, esses mesmos autores, relataram que o número de ciclos de subcultivos agiu diferencialmente sobre as características morfológicas das cultivares de batata.

$\mathrm{Na}$ análise das variáveis massas fresca e seca da parte aérea, foi verificado que não houve diferença em termos de variação entre os subcultivos três e doze para as cultivares 'Aromas' e 'Camarosa'. Para a cultivar 'Camino Real', houve diferença significativa em termos de variação entre os dois níveis de subcultivos. De acordo com o teste F, as maiores variações foram observadas nas plantas submetidas a três subcultivos (Tabela 3 ).

Em relação às massas fresca e seca da raiz, não houve diferença significativa em termos de variação entre os dois níveis de subcultivos para a cultivar 'Aromas'. Para a cultivar 'Camarosa', houve diferença significativa na variação da massa fresca da raiz entre os dois níveis de subcultivos, entretanto, não ocorreu variação na massa seca da raiz. Foi observado que a variação nas massas fresca e seca da raiz foi maior nas plantas com três subcultivos do que doze para esta cultivar. Para a cultivar 'Camino Real', houve diferença significativa na variação das massas fresca e seca da raiz entre os dois níveis de subcultivos. As maiores variações foram observadas nas plantas submetidas a três subcultivos (Tabela 3).

De acordo com o teste $\mathrm{F}$ (Tabela 3 ), não houve diferença significativa em termos de variação na altura das plantas entre os subcultivos para as cultivares 'Aromas'e 'Camino Real'. No entanto, para a cultivar 'Camarosa', houve diferença significativa em termos de variação na altura da parte da aérea das plantas entre os dois níveis de subcultivos, sendo a maior variação observada nas plantas submetidas a três subcultivos. Uma explicação para a variação na característica altura das plantas poderia ser devido a uma possível seleção dos explantes mais vigorosos durante os três ciclos de subcultivos ou que o menor número de subcultivos não tenha sido suficiente para garantir a estabilidade fenotípica das plantas para esta característica na cultivar 'Camarosa'. JAIN (1997) verificou a estabilidade da característica número de flores por planta em somaclones de Begonia e Saintpaulia selecionados de micropropagação em apenas dois ciclos de subcultivos, entretanto, o autor relata que é difícil predizer o número de ciclos de micropropagação quando a estabilidade da característica poderá ser perdida.

Um aspecto que não pode deixar de ser considerado é que os explantes submetidos a três e doze subcultivos, apesar de serem originários do mesmo local e dos mesmos genótipos, foram produzidos em épocas diferentes e, dessa forma, esse fator pode ter influenciado na resposta do genótipo. De acordo com PREECE (2008), sabe-se que diferentes genótipos muitas vezes não respondem da mesma forma, mesmo quando cultivados no mesmo meio.

Para a variável comprimento da raiz o teste $F$ indica que houve diferença significativa em termos da variação entre os dois níveis de subcultivos para a cultivar 'Aromas', sendo a maior variação observada nas plantas submetidas a 12 subcultivos. As cultivares 'Camarosa' e 'Camino Real' não apresentaram diferenças significativas na variação do comprimento da raiz entre os dois níveis de subcultivos (Tabela 3).

Somente a cultivar 'Camarosa' apresentou diferença significativa em termos de variação no número de estolões entre os dois níveis de subcultivos, sendo a maior variação observada nas plantas subcultivadas por três vezes (Tabela 3). 
Tabela 3 - Valores das variâncias dentro das cultivares 'Aromas', 'Camarosa' e 'Camino Real' e dos subcultivos três e doze e teste F para as características massa fresca da parte aérea (MFPA); massa seca da parte aérea (MSPA); massa fresca da raiz (MFR); massa seca da raiz (MSR); altura da parte aérea (APA), comprimento da raiz (CR); número de estolões (NE). UFRRJ, Seropédica, RJ, 2009.

\begin{tabular}{|c|c|c|c|c|c|c|c|c|c|}
\hline \multirow{2}{*}{ Característica } & \multicolumn{3}{|c|}{ 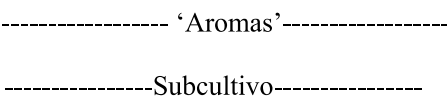 } & \multicolumn{3}{|c|}{-------------- 'Camarosa'--------------- } & \multicolumn{3}{|c|}{-'---------- 'Camino Real' -------------- } \\
\hline & 3 & 12 & $\mathrm{~F}$ & 3 & 12 & $\mathrm{~F}$ & 3 & 12 & $\mathrm{~F}$ \\
\hline MFPA & 14,60 & 11,92 & 1,23 ñs & 60,97 & 78,98 & $1,3 \tilde{\text { ñs }}$ & 49,82 & 20,66 & $2,41 * *$ \\
\hline MSPA & 0,57 & 0,56 & 1,02 ñs & 2,57 & 2,29 & 1,12 ñs & 2,22 & 0,80 & $2,76 * *$ \\
\hline MFR & 0,98 & 1,03 & 1,06 ñs & 3,96 & 2,28 & $1,74 *$ & 1,63 & 0,84 & $1,94 * *$ \\
\hline MSR & 0,02 & 0,04 & 1,54 ñs & 0,15 & 0,12 & 1,31 ñs & 0,06 & 0,03 & $2,19 * *$ \\
\hline APA & 3,68 & 4,93 & 1,34 ñs & 6,95 & 3,90 & $1,78 *$ & 6,05 & 5,04 & 1,2 ñs \\
\hline $\mathrm{CR}$ & 12,79 & 23,91 & $1,87 *$ & 13,11 & 8,61 & 1,52 ñs & 11,59 & 7,93 & 1,46 ñs \\
\hline NE & 1,42 & 1,85 & 1,31 ñs & 5,78 & 2,01 & $2,88 * *$ & 3,81 & 2,84 & 1,34 ñs \\
\hline
\end{tabular}

* Significativo em nível de 5\% de probablidade (Teste F).

** Significativo em nível de $1 \%$ de probablidade (Teste $\mathrm{F}$ ).

ñs - não significativo.

Foi verificada maior estabilidade fenotípica em termos de variação para a cultivar 'Aromas', em comparação com as outras cultivares, pois apresentou menor número de características morfológicas com variação dentro dos subcultivos.

Segundo GAAFAR \& SAKER (2006), às vezes, é difícil diferenciar a variação somaclonal permanente das mudanças epigenéticas transientes, que podem incluir expressões transientes ou modificações de uma característica vegetal. De acordo com JAIN (1997), a estabilidade das características nos somaclones é muito dependente do seu surgimento como um resultado de alterações genéticas ou mudanças epigenéticas. Entretanto, é bastante difícil descobrir essas alterações nas gerações micropropagadas.

Neste trabalho, somente a característica altura da parte aérea após a aclimatização apresentou diferença estatística entre os subcultivos. Esses resultados estão de acordo com os observados por GOMIDE (2004). Esta autora sugere que a falta de diferenças significativas nas características fenotípicas das cultivares de morangueiro 'Vila Nova' e 'Oso Grande' nos diferentes ciclos de subcultivos pode ter sido devido ao pequeno número de ciclos de subcultivos estudados (dois a dez). Segundo RANCILLAC \& NOURISSEAU (1989), não foram observadas diferenças no comportamento de campo em plantas de morango regeneradas com quatro e 19 subcultivos.

Embora as cultivares 'Camarosa' e 'Camino Real' tenham apresentado o maior número de características quantitativas com variação dentro de subcultivos, esta foi observada em plantas submetidas a três ciclos de subcultivos. Isso indica que é possível aumentar para doze ciclos de subcultivos, o que possibilitaria a obtenção de um maior número de mudas micropropagadas, apresentando menor variação nas características fenotípicas. O mesmo resultado não foi observado para a cultivar 'Aromas' que, embora tenha apresentado um comportamento mais estável, com um menor número de características quantitativas com variação dentro de subcultivos, as maiores variações foram observadas em plantas submetidas a doze ciclos de subcultivos.

Neste estudo, na avaliação a campo, as três cultivares apresentaram diferentes repostas quanto às características quantitativas em relação ao número de subcultivos a que os clones foram submetidos, entretanto, não foram observadas plantas aberrantes ou anormais. LÓPEZ-ARANDA et al. (1994) transplantaram para o campo plantas de morangueiro das cultivares 'Chandler' e 'Douglas', oriundas de oito subcultivos in vitro e não foram observadas plantas anormais. Este estudo indicou que provavelmente ambas as cultivares são bastante estáveis e que não há nenhum risco em usar plantas de material micropropagado. NIELSEN \& LOVELL (2000) relataram que a variabilidade observada a nível morfológico pode ser causada pelo hábito de crescimento clonal do morango. Além disso, os clones de muitas espécies têm um alto nível de plasticidade morfológica em resposta às condições ambientais (DE KROONS \& HUTCHINGS, 1995). 


\section{CONCLUSÃO}

Com doze ciclos de subcultivos in vitro de plantas de morangueiro, das cultivares 'Aromas', 'Camarosa' e 'Camino Real', é possível obter mudas em larga escala, sem que ocorram alterações fenotípicas nos clones submetidos a esse processo. A cultivar 'Camarosa' apresentou valores médios superiores para altura da parte aérea, após a fase de aclimatização e a campo, e massas fresca e seca da parte aérea, quando submetida a doze ciclos de subcultivos. As cultivares 'Camarosa' e 'Camino Real' apresentaram maior número de características quantitativas com variação, sendo as maiores variações observadas em plantas submetidas a três ciclos de subcultivos. A cultivar 'Aromas' apresentou uma maior estabilidade nas características fenotípicas em relação aos diferentes ciclos de subcultivo in vitro.

\section{AGRADECIMENTOS} material vegetal.

À Embrapa Clima Temperado, pelo fornecimento do

\section{REFERÊNCIAS}

ARRUDA, A. S. et al. Variação genômica intraclonal de explantes de morango em ambiente controlado. Bioscience Journal, v.22, n.1, p.119-124, 2006.

CALVETE, E.O. et al. Concentração de sacarose no enraizamento in vitro de morangueiro. Horticultura Brasileira, v.20, n.2, p.186$191,2002$.

CASSELLS, A.C.; CURRY, R.F. Oxidative stress and physiological, epigenetic and genetic variability in plant tissue culture: implications for micropropagators and genetic engineers. Plant Cell, Tissue and Organ Culture, v.64, p.145-157, 2001.

D' AMATO, F. Spontaneous mutations and somaclonal variation. In: Nuclear techniques and in vitro culture for plant improvement: International Symposium on Nuclear Techniques and In Vitro Culture for Plant Improvement. 1985. Vienna, Áustria: International Atomic Energy Commision, 1986. p.3-10.

DEBERGH, P.C.; READ, P.E. Micropropagation. In: DEBERGH, P.C.; READ, P.E. (Eds.). Micropropagation technology and application. The Netherlands: Kluwer Academic Pushihers, 1991. p.1-13.

DE KROONS, H.; HUTCHINGS, M.J. Morphological plasticity in clonal plants: the foraging concept reconsidered. Journal of Ecology, v.83, p.143-152, 1995.
EPPO (EUROPEAN AND MEDITERRANEAN PLANT PROTECTION ORGANIZATION). Certification schemes for strawberry. Paris, 2008. 11p.

GAAFAR, R.M.; SAKER, M.M. Monitoring of cultivars identity and genetic stability in strawberry varieties grown in Egypt. World Journal of Agricultural Sciences, v.2, n.1, p.2936, 2006.

GOMIDE, D.G. Influência do número de subcultivos na multiplicação in vitro e na aclimatização de plantas micropropagadas de morangueiro. 2004. 93f. Dissertação (Mestrado em Agronomia) - Faculdade de Agronomia e Medicina Veterinária, Universidade de Passo Fundo, RS.

JAIN, S.M. Micropropagation of selected somaclones of Begonia and Saintpaulia. Journal of Biosciences, v.22, n.5, p.585-592, 1997.

LÓPEZ-ARANDA, J.M. et al. Micropropagation of strawberry (Fragaria $\mathrm{x}$ ananassa Duch.). Effect of minerlas salts, benzyladenine levels and number of subcultures on the in vitro and field behaviour of the obtained microplants and the fuiting capacity of their progeny. Journal of Horticultural Science, v.69, n.4, p.625-637, 1994.

NIELSEN, J.A.; LOVELL, P.H. Value of morphological characters for cultivar identification in strawberry (Fragaria x ananassa). New Zealand Journal of Crop and Horticultural Science, v.28, p.89-96. 2000.

OLIVEIRA, R.P. et al. Produção de matrizes de morangueiro por meio de cultura de tecidos. Pelotas: Embrapa Clima Temperado, 2005. 34p. (Sistemas de Produção, 7).

POLANCO, C.; RUIZ, M.L. AFLP analysis of somaclonal variation in Arabidopsis thaliana regenerated plants. Plant Science, v.162, p.817-824, 2002.

PREECE, J. Stock plant physiological factors affecting growth and morphogenesis. In: GEORGE, E.F. et al. (Eds.). Plant propagation by tissue culture. 3.ed. Dordrecht, The Netherlands: Springer, 2008. p.403-422.

RANCILLAC, M. et al. Incidence de la multiplication in vitro sur le comportement du plant de frasier en France. In: BOXUS, P.; LARVOR, P. (Eds.). In vitro culture of strawberry plants. Cesena: Comission of the European Communities, 1987. p.55-73.

SANTIAGO, G. et al. Variação somaclonal nos descritores mínimos de tubérculo em batata. Ciência Rural, v.42, n.2, p.197$202,2012$.

STEEL, R.G.D.; TORRIE, J.H. Principles and procedures of statistics: a biometrical approach. New York: Mc-Graw Hill, 1981. $633 \mathrm{p}$. 